\title{
Primeiras Experiências de Educação Escolar Tapeba: memórias e relatos
}

\author{
First Experiences of Tapeba School Education: memories and stories \\ Primeras Experiencias de Educación Escolar Tapeba: memorias e historias
}

Recebido: 04/12/2021 | Revisado: 10/12/2021 | Aceito: 15/12/2021 | Publicado: 22/12/2021

\author{
Kátia Coelho Castro de Morais Lopes \\ ORCID: https://orcid.org/0000-0003-4137-1353 \\ Instituto Federal de Educação, Ciência e Tecnologia do Ceará, Brasil \\ E-mail: katyanruben@gmail.com \\ Andréa Moura da Costa Souza \\ ORCID: https://orcid.org/0000-0003-1059-0756 \\ Instituto Federal de Educação, Ciência e Tecnologia do Ceará, Brasil \\ E-mail: andrea.souza@ifce.edu.br \\ Anna Érika Ferreira Lima \\ ORCID: https://orcid.org/0000-0002-8290-9802 \\ Instituto Federal de Educação, Ciência e Tecnologia do Ceará, Brasil \\ E-mail: annaerika@ifce.edu.br
}

\begin{abstract}
Resumo
$\mathrm{O}$ artigo trata das primeiras experiências de escolarização tapebas no município de Caucaia, tendo como objetivo compreender os aspectos que levaram o povo indígena tapeba a iniciar seu processo de escolarização. Para fundamentar este estudo buscou-se pautar em teóricos, leis e artigos que contemplam a temática indígena. A escolha do referido tema ocorreu devido ao pertencimento da mestranda a etnia tapeba, que contou também com orientação das professoras Dra. Andrea Moura da Costa Souza e Dra. Anna Erika Ferreira Lima, docente do curso de Mestrado Profissional em Ensino e Formação Docente UNILAB-IFCE. A metodologia utilizada foi a pesquisa bibliográfica, e documental, realizando um estudo de caso em que se utilizou da aplicação de um questionário (Google Forms) respondido por três docentes tapebas. Durante as leituras para a redação do trabalho percebe-se que os autores têm um olhar acurado sobre as experiências escolares tapebas e que os professores que participaram do questionário têm uma percepção que converge com o referencial teórico, levando-nos memorar e a compreender de forma abrangente o início da escolarização tapeba, suas lutas e demandas pelo ensino diferenciado.
\end{abstract}

Palavras-chave: Escolarização Indígena; Experiências Educacionais; Ensino Diferenciado.

\begin{abstract}
The article deals with the first experiences of tapebas schooling in the municipality of Caucaia, aiming to understand the aspects that led the tapeba indigenous people to start their schooling process. To support this study, we sought to base ourselves on theorists, laws and articles that address the indigenous theme. The choice of this topic was due to the master's belonging to the Tapeba ethnic group, who also had the guidance of Dr. Andrea Moura da Costa Souza and Dr. Anna Erika Ferreira Lima, professor of the Professional Master's Degree in Teaching and Teacher Training course UNILAB- IFCE. The methodology used in parts the bibliographical research, having as a qualitative approach in which it was used the application of a questionnaire (Google Forms) answered by three tapebas professors. During the readings for the writing of the work, we realized that the authors have an accurate look at the subject and that the teachers who participated in the questionnaire have a perception in line with the theoretical framework, leading us to understand in a comprehensive way the beginning of tapeba schooling, their struggles and demands.
\end{abstract}

Keywords: Indigenous Schooling; Educational Experiences; Differentiated Teaching.

\section{Resumen}

El artículo trata sobre las primeras experiencias de escolarización tapebas en el municipio de Caucaia, con el objetivo de comprender los aspectos que llevaron al pueblo indígena tapeba a iniciar su proceso de escolarización. Para sustentar este estudio, buscamos basarnos en teóricos, leyes y artículos que abordan el tema indígena. La elección de este tema se debió a la maestría perteneciente a la etnia Tapeba, que también contó con la orientación de la Dra. Andrea Moura da Costa Souza y la Dra. Anna Erika Ferreira Lima, profesora del curso de Maestría Profesional en Docencia y Formación Docente. UNILAB- IFCE. La metodología utilizó en partes la investigación bibliográfica, teniendo como enfoque cualitativo en el que se utilizó la aplicación de un cuestionario (Google Forms) respondido por tres profesores de tapebas. Durante las lecturas para la redacción del trabajo, nos dimos cuenta de que los autores tienen una mirada certera del tema y que los docentes que participaron en el cuestionario tienen una percepción acorde con el marco teórico, lo que nos lleva a comprender de manera integral el tema. inicio de la escolarización tapeba, sus luchas y demandas.

Palabras clave: Escolarización Indígena; Experiencias Educativas; Enseñanza Diferenciada. 


\section{Introdução}

Ao verificarmos a situação atual dos povos indígenas, principalmente no estado do Ceará, nos deparamos com etnias que estão fortalecendo e perpetuando sua transmissão cultural, social, territorial, política e religiosa através do processo de escolarização. A exemplo disso temos o povo Tabepa, localizado no município de Caucaia/Ce, que desde da década de 80 tem seu reconhecimento como uma etnia e firmamento de sua cultura, e a partir da década de 90 iniciam o processo de escolarização dentro de suas aldeias na tentativa de não só estimular sua cultura, mas de oportunizar seus descendentes o acesso a novos contextos que diferem de suas tradições e possibilitam o ingresso das crianças e jovens índios ao mundo do trabalho, assim como ao conhecimento científico, político e social de forma abrangente.

Sendo assim, nosso objeto de estudo é como foi idealizado as primeiras experiências de ensino a esse povo e quais os motivos que levaram aos Tapebas a buscar um processo de ensino aprendizagem que contemplasse suas especificidades como tribo indígena. Tendo como principal objetivo compreender os aspectos que levaram o povo indígena tapeba a iniciar seu processo de escolarização. Nossa motivação vem do fato de ser pertencente a comunidade indígena e participantes do movimento social que busca a garantia não só de uma educação de qualidade adaptada, mas também de acesso à saúde, demarcação de terras entre outros fatores que movem toda luta e militância Tapeba.

Nossa metodologia foi a bibliográfica e documental, realizando um estudo de caso associado com uma abordagem qualitativa, onde verificamos a existência de um rico material sobre os povos tapebas e suas organizações educacionais e sociais. Buscando solidificar e embasar todo conhecimento encontrado.

$\mathrm{O}$ artigo está dividido em quatro seções, sendo a primeira a introdução, a segunda o percurso metodológico, a terceira, os resultados, subdivida em: análise sobre o surgimento das escolas tapebas, o perfil dos alunos que frequentam essas escolas e o histórico da Escola Indígena Tapeba Amélia Domingos, e a descrição do estudo de caso que apresenta no todo conteúdo coletado em diálogos com docentes indígenas e informação através dos teóricos, e das coletas de dados, na quinta e última temos as considerações finais.

\section{Metodologia}

O percurso metodológico foi baseado em parte a pesquisa bibliográfica, onde foi realizada a leitura de autores que abordam a temática, além da aplicação de um questionário (Google Forms) que foi respondido por três professores que atuam a mais de 10 anos na área da educação indígena, buscando assim um estudo solidificado e concreto sobre as questões investigadas. A abordagem qualitativa que de acordo com Minayo (2016, p.20) abordagem caracteriza-se como qualitativa, uma vez que esta "responde a questões particulares", além de abranger diversos significados e "um nível de realidade que não pode ser quantificado", sendo adotada com intuito de aprofundar nosso conhecimento e verificar se há ligação entre os textos estudados com a realidade escolar apresentada em cada questionário.

O papel dos elementos a serem recolhidos será fundamentalmente o de reforçar, apoiar e justificar as ideias pessoais formuladas pelo autor do trabalho. Estes elementos retirados das várias fontes dão às várias afirmações do autor, além do material sobre o qual trabalha, a garantia de maior objetividade fundada no testemunho e na verificação de outros pensadores (Severino, 1984, p.116).

Desta forma, ao utilizarmos a pesquisa bibliográfica unindo ao material colhido durante as entrevistas e a análise de documentos pertencentes a instituição escolar que foi o locus de nossa ação, teremos uma perspectiva mais concreta sobre o assunto, deixando de lado a superficialidade e trazendo informações sobre o surgimento das escolas tapebas, o perfil dos alunos que frequentam essas escolas e o histórico da Escola Indígena Tapeba Amélia Domingos, além dessas informações documentais e bibliográficas, traz-se os diálogos com docentes indígenas. 


\section{Resultados}

\subsection{O Surgimento das Escolas Indígenas Tapebas}

A Escola Tapeba tem sua origem em meados dos anos 90, onde as primeiras aulas eram ministradas embaixo de um cajueiro na aldeia Lagoa do Tapebas, não se tinha a princípio estrutura e material didático necessário para sua funcionalidade, o que se tinha era doações de pessoas e instituições que visitavam a escola. Em períodos chuvosos as aulas eram paralisadas por não haver sala coberta apropriada para abrigar os alunos da chuva. Contudo, durante muito tempo a escola funcionou assim.

Desde os anos 1990, o movimento indígena vem, cada vez mais, evidenciando suas estratégias de visibilização e rearticulação da diferença colonial, mesmo que essas estratégias se tenham modificado no decorrer do tempo. Por exemplo, as grandes mobilizações, desde 1990, conferiram visibilidade e construíram uma base étnica de política de resistência, alterando a percepção generalizada sobre os povos indígenas, considerados camponeses rurais e peões, rumo à sua compreensão como atores sociais e políticos. Tal mudança forneceu as bases não somente para um novo reconhecimento do e através do movimento indígena, mas também, o que é mais importante, para a corroboração de uma organização sociopolítica dentro do movimento em si, tanto em nível local quanto nacional. (Walsh, 2019, p. 27 28).

A partir da luta tapeba, houve uma mobilização para o inicio das escolas indígenas nas aldeias e comunidades. De acordo com Walsh fica claro que o fortalecimento desse movimento proporcionou uma nova visão sobre o índio, ate então considerado um camponês, peão agricultor, agora visto como um sujeito com direitos e necessidades especifica. Uma dessas necessidades é a escola diferenciada indígena com uma base curricular própria. Esse modelo de instituição de ensino surge como um escape para as crianças tapebas, que moravam longe das demais escolas e sofriam com o preconceito por parte de professores, alunos e a comunidade não-indigena, os quais lhe chamavam de "comedores de carniça", "bacurim" e "pernas de pau" e no ambiente das relações interpessoais da escola, deve-se compreender o indivíduo com suas diferenças e qualidades (Campos \& Godoy, 2013). De modo que esse histórico de perseguição levou as lideranças a organizarem suas próprias instituições de ensino.

A presença dos tapebas na região de Caucaia é caracterizada pela ocorrência de conflitos ligados a situações de preconceito. Tais situações marcam, decisivamente a trajetória histórica do grupo, apresentando-se, na memória dos índios, como cenas que colocam em primeiro plano as relações de poder entre regionais e suas comunidades. (Nascimento, 2009, p.43.)

$\mathrm{Na}$ fala do autor notamos que os abusos sofridos pela população indígena foi algo que impulsionou uma mudança nas relações índio - sociedade, o quadro de preconceito era algo ruim, por que não canalizá-lo para se fazer algo construtivo. Com esse pensamento as lideranças comunitárias, anciões e as comunidades se mobilizam e começam a investir em seu próprio método de ensino. Com sete anos de funcionamento em condições precárias, finalmente as escolas tapebas recebem um convênio com a Secretária de Estado do Ceará - SEDUC, que constrói e reconhece a primeira escola indígena de um acordo que previa a construção de 12 escolas, uma em cada comunidade tapeba. Sendo assim, a comunidade indigígena vislumbra os resultados de suas lutas, quando o estado do Ceará começa a reconhecer e amparar as escolas indígenas. A Lei de Diretrizes e bases da educação em seu artigo 78 diz:

Desenvolvimento de programas integrados de ensino e pesquisa, para oferta de educação escolar bilíngüe e intercultural aos povos indígenas, com os objetivos de: proporcionar aos índios, suas comunidade e povos, a recuperação de suas memórias históricas, a reafirmação de suas identidades étnicas; a valorização de suas línguas e ciências; e garantir aos índios, suas comunidades e povos o acesso às informações, conhecimentos técnicos e científicos da sociedade nacional e demais sociedades indígenas e não indígenas.(LDB, art.78). 
Começam, assim a dar o primeiro passo para fazer valer o que está escrito na lei, garantir o direito à educação indígena contemplando componentes curriculares que valorizem suas culturas, tradições, identidade e que fortaleçam suas crenças. Esse primeiro modelo de escola foi edificado em formato circular, trazendo então a experiência do círculo que é feito durante o Toré (ritual indígena feito em roda). Atualmente a única escola tapeba que não possui prédio próprio é a Escola Tapeba de Capuan. As demais comunidades foram beneficiadas com a construção de seu espaço físico.

Mesmo com esse avanço por muito tempo foi desvalorizado o ensino Tapeba, pois foi considerando como inferior, incompleto e que deixava a desejar diante do ensino tradicional, pensamento que permeia a mente da população não indígena como forma de continuar subjugando os tapebas.

Até hoje, as escolas indígenas no Ceará enfrentam problemas relacionados a sua aceitação ou legitimação. Sua inserção no contexto de etnogêneses reflete os conflitos inerentes às interações sociais decorrentes desse processo. Sendo assim, num cenário de disputas a escola procura afirmar sua legitimidade entre os autores internos (índios) e externos (não-índios). (Nascimento, 2009. p,88).

Fica bem claro que ainda existe resistência à aceitação das instituições de ensino tapebas por parte dos não indígenas, mas mesmo nesse cenário ainda há a credibilidade que a comunidade indígena e os órgãos competentes têm da formação dos discentes tapebas. Esse merecimento que foi conquistado tem dado força para os tapebas continuarem suas lutas por uma educação indígena diferenciada e intercultural de qualidade.

É importante destacar que a interculturalidade mobiliza processos dinâmicos em várias direções, cheios de criatividade e tensões e em permanente construção. Processos enraizados nos diversos universos socioculturais atuais, caracterizados por relações de poder e pelas grandes desigualdades sociais, políticas e econômicas. Este talvez seja o maior desafio da interculturalidade e também da educação intercultural, não ocultar as desigualdades, as contradições e conflitos das sociedades atuais, mas trabalhar com e intervir neles. (Sacavino, 2020, p. 8)

No ensino tradicional as desigualdades são ocultadas, já na perspectiva de ensino indígena tapeba essas contradições são usadas para gerar discentes capazes de reconhecerem suas próprias identidades étnicas e aceitar sua cultura como algo importante e não como um fator para desvaloriza-lo.

\subsection{Escolas Tapebas: Os discentes}

Os alunos das escolas indígenas tapebas são caracterizados por fazerem parte dessa etnia e por estarem presentes em aldeias e comunidades indígenas que em sua maioria estão localizadas em áreas de risco, insegurança e marginalizadas. Temos então um perfil de aluno carente, onde em grande parte o único lazer que conhecem é o que a própria escola oferece. Na percepção de ensino, os alunos aprender o necessário para o mundo do trabalho, para a vida em sociedade, para o desenvolvimento do pensamento crítico, além de recebe a formação necessária para sua aldeia, época do plantio, fabricação de utensílios de caça, preservação de suas terras, o histórico de seu povo, a espiritualidade e a encantaria, além do senso de pertencimento a algo maior que é sua etnia, tribo ou povo. É imprescindível entender que a educação deve permear as ações dos seres humanos na conquista dos seus objetivos, no ir e vir dos seus passos e na consolidação dos seus direitos sociais. (Bissaro et al., 2021, p.5)

Acompanhemos os pensamento de Marra (2014,p.3) que diz que: O aluno 'índio' é, como no passado colonial brasileiro, visto com desconfiança, com reservas, talvez com certo desprezo, por uma classe social estabelecida e privilegiada. Esse pensamento colonial presente na sociedade é algo que nos remete novamente ao pensamento de desmerecimento das escolas indígenas. Que além de constante na desconfiança de que haja um ensino de qualidade, também se mostra na perspectiva de que se existe um aluno indígena apto ao ensino educacional. Analisando as situações percebemos que 
novamente surge um estigma sobre os alunos tapebas e sobre o ensino prestado a eles. Observa-se que há uma exclusão desse discente gerada por um preconceito.

Mesmo com os julgamentos sobre o ensino tapeba, seus professores e alunos, entende-se que esse espaço de construção escolar indígena se tornou algo propício ao ensino, antes muitos alunos da etnia tapeba não concluíam seu ensino médio, ou ainda cursaram até fundamental anos finais, hoje a realidade é outra, pois com as escolas tapeba, o índio sente-se contextualizado e aceita sua identidade, assim vários alunos conseguiram retomar seus estudos, além dos que chegaram aos cursos de ensino superior. Em um espaço escolar que se baseia na inclusão, a participação ativa de todos os estudantes juntos, são necessárias práticas que garantam o desenvolvimento de aprendizagens e que possibilitem a continuidade dos estudos (Magalhães et al., 2021, p.5).

No site da Fundação Nacional do Índio - FUNAI diz:

O número de ingressantes e concluintes indígenas nas universidades públicas e privadas do país aumentou significativamente no ano de 2016 em relação a 2015. De acordo com dados mais recentes do Instituto Nacional de Estudos e Pesquisas Educacionais Anísio Teixeira (Inep), o número de alunos ingressantes cresceu 52,5\% e o de concluintes, 32,18\%. (FUNAI, 2018)

Os dados apresentados acima comprovam que há realmente um aumento de indígenas nas universidades, esse processo de educação escolar indígena tem proporcionado aos índios sua entrada ao ensino superior. Esses dados confirmam a participação da população indígena tapeba, que se encontra inserida nesses números.

Apesar de todas as discriminações sofridas, vemos que os alunos, os professores, a escola tapeba em si resistem e prosseguem seu caminho, traçando uma linguagem educacional única, onde mesmo com todo o mecanismo do sistema sendo desfavorável, conquistou o seu espaço e superou a expectativa de muitos.

\subsection{Histórico da Escola Indígena Tapeba Amélia Domingos}

Localizada na Aldeia indígena tapeba de Jardim do Amor, Caucaia/Ce, a escola indígena Tapeba Amélia Domingos tem seu início no dia 15 de junho de 1998, no quintal da residência de dona Leene de Abreu (liderança indígena da comunidade da época). Sua funcionalidade se dava em três turnos sendo eles manhã, tarde e noite, onde se tinha as seguintes modalidades: educação infantil, ensino fundamental e uma turma de educação de jovens e adultos. Seus primeiros professores foram: Salomé de Abreu (primeira diretora da escola), Clebe Nogueira e Michele, pessoas que pertenciam à comunidade indígena e que tinham terminado o ensino médio. Na resolução 382/2003 do Conselho de Educação do Ceará - CEC, capítulo XI encontramos:

Art. 13 - A formação de professores será específica, diferenciada e orientada pelos referenciais para a formação de professor indígena e legislação pertinente. Art. 14 - A atividade docente na escola indígena será exercida, preferencialmente, por professor oriundo da etnia. Parágrafo único - Será garantida a formação em serviço, conforme a legislação vigente. Art. 15 - A Secretaria da Educação Básica será responsável pela definição da política de formação de professor indígena, assim como de sua execução. Parágrafo único - Os cursos de formação de professor indígena serão organizados com a participação de representantes dos povos e comunidades indígenas.

Vemos que só no ano de 2003 o Conselho de Educação do Ceará - CEC, dispõe uma resolução que ampara os professores indígena quanto a sua formação específica e em serviço, além de assegurar que os educadores deveriam pertencer aos povo/tribo/etnia da comunidade onde atuariam. Nos primeiros anos de funcionamento os docentes que trabalhavam na escola, não disponham de formação, nem de materiais didáticos, nem de um lugar próprio para o ensino, muito menos de 
salário. Sendo que apenas em 2001 a Secretaria de Educação do Ceará - SEDUC, começou a dar suporte para que essa escola tivesse condições reais para o ensino e aprendizagem, assim a partir desse ano os docentes começaram a ser remunerados.

No ano de 2006, com muito esforço os funcionários e a comunidade se reuniram e fizeram um empréstimo para construção de quatro salas para o funcionamento da escola, sendo uma cozinha e as outras três serviam como sala de aula. Somente em 2009 a aldeia foi contemplada com um espaço físico. Foram então 11 anos esperando para que as crianças tapebas da comunidade de Jardim do Amor pudessem ter um espaço educacional digno. Ainda dentro da resolução do CEC $\mathrm{n}^{\circ}$ 383/2003, o capítulo X traz os seguintes artigos:

Art. 12 - O prédio, as instalações, os equipamentos da escola indígena e as suas concepções de espaço devem ser adequados às necessidades dos índios e responder às aspirações de seu povo ou de sua comunidade, atendidas, no mínimo, as orientações seguintes: a) O prédio escolar com estrutura definida pela comunidade de comum acordo com as respectivas Secretarias de Educação deverá ser suficiente para abrigar os alunos em condições satisfatórias, abrangendo: habilidade, segurança, higiene e conforto. Deverá ter água potável, alguma forma de energia elétrica e instalações sanitárias suficientes para a demanda e adequadas aos padrões utilizados; b) Os recursos didáticos, o mobiliário e as instalações deverão ser adequados e suficientes para o desenvolvimento do Projeto - Político Pedagógico; c) $\mathrm{O}$ acervo bibliográfico deverá atender às exigências das necessidades culturais e à faixa etária dos alunos.

Legalmente falando há muito tempo os povos indígenas têm o direito à educação, diferenciada, específica, bilíngue, intercultural e organização política-social garantida, mas verificando os fatos que constroem a história da fundação das escolas, percebe-se que falta uma celeridade nesses processos, o próprio conselho de educação do estado em 2003 criou uma resolução que abrange essas instituições educacionais, contudo, apenas vários anos depois que as populações indígenas são realmente contempladas.

Atualmente a escola indígena Tapeba Amélia Domingos, dispões de prédio próprio, professores pertencentes a etnia tapeba que já possuem graduação, a SEDUC/Ce é a entidade mantenedora, são oferecidas as modalidades de creche, educação infantil, ensino fundamental anos iniciais e finais e educação de jovens e adultos, tendo 130 alunos matriculados. O núcleo gestor é composto por uma diretora, uma coordenadora pedagógica, uma secretária e um assessor financeiro. Para Mota, Dantas e Dublante (2021) a gestão escolar:

Apesar de algumas ressalvas, a escola vem vivenciando princípios da descentralização do poder, da participação e da autonomia. Para que a participação realmente aconteça de forma efetiva é necessário que a equipe diretiva seja formada por pessoas que tenham conhecimento prático e teórico possibilitando uma visão diferenciada com atitudes que norteiam os princípios da gestão democrática. É importante conhecer o significado de cada um dos mecanismos para poder vivenciá-los, visto que o conhecimento é o primeiro aspecto para proporcionar uma mudança social, no caso da escola, uma mudança de práticas e de posturas administrativas e pedagógicas. (Mota; Dantas; Fernandes \& Dublante, 2021, p.3)

Levanto em conta o que o autor disse o núcleo gestor da Escola Indígena desempenha papeis de autonomia e de democracia onde cada um trabalha dentro da sua funcionalidade, mas sempre abrindo espaço para a participação da comunidade escolar em geral. No quadro de funcionários ainda encontramos dois serviços gerais, uma merendeira, um porteiro e quatro vigilantes patrimoniais.

Dispondo de laboratório de informática e sala de multimeios, um campinho e um parquinho para lazer e atividades dos alunos, recentemente foi contemplada com uma reforma e ampliação para atender a demanda de novas turmas e ao aumento de procura por matrículas.

A gestão da escola evidenciou que ainda sente falta de uma maior colaboração das entidades estatais, mas visto do que já foi realizado e feito a satisfação de poder ofertar um espaço e ensino de qualidade aos alunos indígenas e presente na fala. Mensalmente a instituição de ensino recebe a visita de uma superintendente da CREDE 01, que realiza uma vistoria técnica nas 
dependências da escola e na sistematização pedagógica. Auxiliando também no planejamento dos professores. O projeto político pedagógico foi construído pela comunidade escolar, sendo atualizado todos os anos juntamente com o regimento. A principal possibilidade de construção do PPP passa pela relativa autonomia da escola, de sua capacidade de delinear sua própria identidade, isto significa resgatar a escola como espaço público, lugar de debate, do diálogo fundado na reflexão coletiva (Veiga, 2007, p.14).

Dentro da perspectiva intercultural, são ministrados aos alunos aulas voltadas a cultura, espiritualidade, artesanato, expressão corporal, territorialidade, identidade e pertencimento, valorizando os saberes tradicionais e os "troncos velhos" (anciões da aldeia). Na visão de Padre Bartolomeu de Meliá temos:

A educação indígena é certamente outra. Ela está mais perto da noção de educação, enquanto processo total. A convivência e a pesquisa mostram que para o índio a educação é um processo global. A cultura indígena é ensinada e aprendida em termos de socialização integrante. $O$ fato dessa educação não ser feita por profissionais da educação, não quer dizer que ela se faz por uma coletividade abstrata. (...) a educação de cada índio é interesse da comunidade toda. A educação é o processo pelo qual a cultura atua sobre os membros da sociedade para criar indivíduos ou pessoas que possam conservar essa cultura. (MELIÁ, 1979.p.17).

Essas especificidades que são contempladas e inseridas como componente curricular fortalecem todo o movimento de luta indígena, através da perpetuação do conhecimento e dos saberes. Tal fato contribui significativamente para a sobrevivência dessas etnias, por isso a importância do processo de escolarização do índio ser gerido e voltado para aldeia/comunidade.

\section{Discussões}

Participaram deste estudo 03 professoras que estão a mais de 10 anos trabalhando na escola Indígena Tapeba Amélia Domingos, são elas: Maria Ferreira formada em pedagogia pela Faculdade Excelência - FAEX, possui magistério indigena e atualmente cursa a Licenciatura Intercultural Indigena PITAKAJÁ, oferecida pela Universidade Federal do Ceará, Marta da Silva formada em pedagogia pela Faculdade Kurios, possui magistério indígena e Meire da Costa, formada em pedagogia pela Faculdade Kurios, tem pós graduação em Gestão e Coordenação Escolar pela Faculdade Plus e possui magistério indigena, foi uma das primeiras professoras da escola e atualmente atua na gestão como diretora escolar. Os nomes das docentes que participaram da entrevista foram trocado por nomes fictícios.

Ao conversarmos com cada uma individualmente, percebe-se um alinhamento do discurso oral, assim como há um vínculo com todo material coletado seja documental ou bibliográfico. Começamos nossa conversa com a seguinte pergunta: por que uma educação escolar indigena? Onde encontramos como resposta "a necessidade de preservar a diferença cultural de nosso povo" (Meire), na escola convencional os alunos não tinham a liberdade de expressar sua cultura de forma aberta, além de não trabalhar conceitos que são essenciais para os povos indígenas como a territorialidade e a espiritualidade. Diante desse exposto encontramos na Constituição Federal:

Art- 210 - Serão fixados conteúdos mínimos para o ensino fundamental, de maneira a assegurar formação básica comum e respeito aos valores culturais e artísticos, nacionais e regionais. 2. O ensino fundamental regular será ministrado em língua portuguesa assegurada às comunidades indígenas também a utilização de suas línguas maternas e processos próprios de aprendizagem.

É claro na legislação brasileira que os discentes indígenas têm direito a uma formação voltada para sua diversidade cultural, assegurando também a construção de processos próprios de aprendizagem. Antes das escolas indígenas, os índios frequentavam a escola convencional, o que deixava a desejar quando se relacionava a manutenção do estilo de vida desse povo. 
$\mathrm{Na}$ fala das docentes, essa marca de preservação cultural através da escolarização é notória, sendo ainda mais reforçada com o artigo da Constituição Federal Brasileira, Ferreira, Evênio, Sousa \& Souza (2021, p.7) diz o seguinte: nesse sentido do educar, do formar, que concebemos a escola básica atual e os profissionais que nela atuam, em especial, os professores.

Questionamos também se esse processo de escolarização indígena foi algo que surgiu de maneira acessível tanto a comunidade, como para os professores e alunos, obtivemos como resposta: "Tudo na vida do índio vem da "luta", da mesma forma a educação indígena veio por meio de muito esforço e batalha do povo" (Marta). A palavra "luta" está grifada na fala de todos os pertencentes a etnia tapeba, chega ser uma transmissão hereditária, cultural, social e política, sendo assim a busca por uma educação de qualidade e diferenciada vem da militância de toda aldeia.

O que importa principalmente ao movimento de professores indígenas, é precisamente a luta pelo direito dos povos indígenas terem em mãos o poder sobre os programas de educação escolar que se desenvolvem em suas áreas, uma vez que se constituem instrumentos imprescindíveis na construção de direitos. (M.F. da Silva, 1994, p.48)

Como alternativa de resistência à imposição de um ensino aprendizagem que não atendia as necessidades e expectativas dos discentes indígenas, a escola diferenciada vem modificando essa escolarização, devido principalmente a atuação e participação dos povos indígenas à formulação de suas diretrizes, currículos específicos e programas voltados ao fortalecimento do interculturalismo.

Ainda durante nosso diálogo, foi indagado sobre como se deu os primeiros magistérios indígenas e qual sua importância para a educação escolar indígena, "os magistérios começaram no ano 2000, a SEDUC fornecia os materiais, hospedagens e alimentação necessária para essas formações, cada etapa do magistério era realizado em aldeias diferentes, o que oportunizou a troca de saberes e conhecimentos com outros povos indígenas do Ceará. Era um tempo difícil, mas foi bastante satisfatório, quando começou a escola indígena não se tinha formação ou graduação nenhuma, com os magistérios (dava direito a lecionar até $5^{\circ}$ ano do fundamental anos iniciais) amenizou um pouco essa situação" (Maria). No Plano Nacional de Educação temos a meta 17 que diz: Formular, em dois anos, um plano para a implementação de programas especiais para a formação de professores indígenas em nível superior, através da colaboração das universidades e de instituições de nível equivalente (PNE, 2001). Apesar dos magistérios indígenas começarem no ano de 2000, apenas em 2001 o PNE trouxe como um objetivo a ser alcançado.

Vemos três aspectos nas falas das professoras que são bases para a escola indigena tapeba: preservação da diferença cultural, a luta como meio de conquistar seus direitos e a formação de professores para suprir as necessidades do novo ensino que surge dentro das Aldeias. Evidenciando que outros fatores constroem e auxiliam o desenvolvimento do ensino diferenciado tapeba, mas o que apuramos nessa investigação apontou esses como pilares iniciais do processo de escolarização.

\section{Considerações Finais}

Por muito tempo a educação para os indígenas foi realizada sem contemplar certas especificidades que os povos originários têm em sua cultura, espiritualidade, organização político-social, territorialidade e identidade. Levando a vários anos de processos de escolarização falhos e desgastantes, o que ocasionou uma grande desistência de alunos índios a frequentar a escola.

Ao nos deparamos com a tribo tapeba, localizada no município de Caucaia/Ce, vemos que esse fato se repetia, até que seus membros, resolveram iniciar, primeiramente, de forma independente suas formas de ensino, adiante verificamos que entidades estatais assumiram seu papel social e político na construção e legalização dessas primeiras escolas indígenas.

Desde do Brasil colonial, o índio é visto como indivíduo que deveria ser agregado a "vida em sociedade", para a cultura européia da época a educação indígena era um meio de inseri-los e até mesmo "salvá-los", assim surge os aldeamentos 
Jesuítas como primeiras formas de educar os povos que aqui habitavam. Claro que esse modelo educacional passava bem distante de um verdadeiro ensino aprendizagem. Logo os indígenas rejeitaram e resistiram a esse método.

Não diferente, a educação secular não buscava oferecer aos discentes indígenas uma educação intercultural que abrange questões não só de cunho científico-social, mas que o levasse a refletir sobre questões de sua aldeia, povo, cultura, identidade, espiritualidade, territorialidade e expressão. Tornando então o acesso à escola algo que fora do desejo das crianças indígenas.

Com a educação escolar indigena diferenciada, não só houve um retorno dos alunos que estavam em situação de abandono, como uma crescente procura por matrícula, assim a escola indígena demonstrou-se como uma ferramenta eficaz na transmissão de saberes ancestrais, culturais, sociais e espirituais, necessários à formação dos jovens índios. A escola torna-se palco então de movimentos militantes, comunitários e educacionais.

Nossos principais objetivos foram justificados, através da compreensão do início das escolas indígenas, que surge neste contexto de luta por terras e de uma busca por um renascimento cultural, onde os indígenas pudessem mostrar e memorar suas origens sem medo de repreensão ou críticas.

Vemos que existe sim uma necessidade de ensino diferenciado para atender as carências desse povo, uma escola onde os alunos possam afirmar sua identidade e herança cultura, claro sem danificar o ensino secular, mas abrindo um espaço para passa-lhes um significado de ser discente indígena, de ser tapeba e de que é preciso lutar para afirmar sua cultura e sua origem.

Conseguimos compreender seu surgimento e atual organização, verificamos seus crescimento e suas principais demandas, a formação de seus profissionais e as características de seus publico alvo. Ficando então as seguintes questões para que merecem ser investigadas: se há uma diferenciação no processo avaliativo e como é gerido o currículo escolar.

\section{Agradecimentos}

Agradecemos a todos que direta e indiretamente contribuíram para a realização e sucesso do artigo.

\section{Referências}

Bissaro, D. Z., Elias, E. M. C., Becevelli, S. L., Costa, S. M., \& Costa, T. G. F. (2021). Evasão e abandono escolar: os desafios de conter seu avanço, as causas e consequências- estudo de caso na Escola Municipal "João Mendonça", em Teixeira de Freitas- Bahia. Research, Society and Development, 10(4), 34810412463. https://doi.org/10.33448/rsd-v10i4.12463

Brasil. (1988). Constituição da República Federativa do Brasil. Centro Gráfico, 1988.

Brasil. (1996). Lei de Diretrizes e Bases da Educação nº9.394.; MEC.

Brasil. (2001). Plano Nacional de Educação. MEC.

Brasil. (2019). Cresce o número de estudantes indígenas nas universidades. Website da Funai. http://www.funai.gov.br/index.php/comunicacao/noticias/4720cresce-o-numero-de-estudantes-indigenas-nas-universidades

Campos, C. R. D., \& Godoy, M. A. (2013). Relações interpessoais: um desafio para o gestor escolar.Seminário Internacional de Seminário Internacional de Representações Sociais, Subjetividade e Educação e Seminário Internacional sobre Profissionalização Docente, 2.

Ceará. (2003). Resolução n. 382/2003. Dispõe sobre a criação e o funcionamento de escola indígena no Sistema de Ensino do Ceará e dá outras providências. https://www.cee.ce.gov.br/wp-content/uploads/sites/49/2011/08/RES-0382-2003.pdf.

Ceará. (2010). Histórico das escolas indígenas. Website Seduc $\quad$ Ceará. https://www.seduc.ce.gov.br/wpcontent/uploads/sites/37/2010/05/historico_escolas_indigenas.pdf.

Magalhães, T. C., Diaz-Rodriguez, F. M., Fagundes, D. D. A., Santos, M. O. F., Prado-Netto, A., Xará, G. M. S., Xará, F. B. do N. S., Walhbrinck, E. R., \& Porto, R. S. de O. (2021). Educação inclusiva: autoconceito profissional de professores. Research, Society and Development, $10(11)$, e248101118719. https://doi.org/10.33448/rsd-v10i11.18719

Ferreira, T. F., Evêncio, K. M. de M., Sousa, A. P. P. de, \& Souza, L. P. (2021). Considerações sobre os desafios da escola básica atual: reflexões para uma sociedade mais plural. Research, Society and Development, 10(4), e29210414036. https://doi.org/10.33448/rsd-v10i4.14036

Marra, M. L. M. P. (2014). Inclusão-exclusão: o aluno indígena no cenário da universidade pública: reflexões sobre o sistema de cotas universitárias. Rev. Eletrônica Pesquiseduca. 6(11), 216-230. 
Research, Society and Development, v. 10, n. 17, e156101724346, 2021

(CC BY 4.0) | ISSN 2525-3409 | DOI: http://dx.doi.org/10.33448/rsd-v10i17.24346

Meliá, B. (1979). Educação indígena e alfabetização. Edições Loyola. (Coleção "Missão Aberta"). 50 p.

Minayo, M. C. S. (2016). O desafio da pesquisa social. In S. M. Maria Cecília (org.), F. D. Suely, G. Romeu. Pesquisa social: teoria, método e criatividade. Série Manuais Acadêmicos. 9-28. Vozes.

Mota, P. A. T., Dantas, C. W. M., Fernandes, L. S. L., \& Dublante, C. A. S. (2021). Democratização da gestão escolar: mecanismos de participação na escola. Research, Society and Development, 10(12), e374101220297. https://doi.org/10.33448/rsd-v10i12.20297

Nascimento, R. G. D. (2009). Rituais de Resistência: Experiências pedagógicas Tapebas. Natal: Teses (Doutorado em Ciências da Educação) - Programa de Pós - Graduação em Educação do Centro de Ciências Sociais da Universidade Federal do Rio Grande do Norte. 209 p.

Sacavino. S. B. (2020). Interculturalidade e Práticas Pedagógicas: construindo caminhos Revista do Centro de Educação UFMS. 45(1). 1-18.

Severino, A. J. (1984). Metodologia do trabalho cientifico: diretrizes para o trabalho didático cientifico na Universidade. Cortez Editora. 11, $195 \mathrm{p}$.

Silva, M. F. D. (1994). A conquista da escola: Educação escolar indígena e movimento de professores indígenas no Brasil. Brasilia: MEC/INEP. XIV(63), 38-53.

Veiga, I. P. (2007). Projeto Político-Pedagógico da escola: uma construção possível. Papirus, 23. 11-35.

Walsh. C. (2019). Interculturalidade e Decolonialidade do Poder: Um pensamento e posicionamento "outro" a partir da diferença colonial Revista Eletrônica da Faculdade de Direito da Unversidade Federal de Pelotas. 05(1), 6-39. 